\title{
HuR interacts with human immunodeficiency virus type I reverse transcriptase, and modulates reverse transcription in infected cells Julie Lemay ${ }^{1,2,5}$, Priscilla Maidou-Peindara ${ }^{1,2}$, Thomas Bader ${ }^{1,2}$, Eric Ennifar ${ }^{3}$, Jean-Christophe Rain ${ }^{4}$, Richard Benarous*1,2,6 and Lang Xia Liu*1,2,7
}

Address: ${ }^{1}$ Institut Cochin, Université Paris Descartes, CNRS (UMR8104), Paris, France, ${ }^{2}$ Inserm, U567, Paris, France, ${ }^{3}$ Architecture et réactivité de l'ARN, UPR 9002 CNRS, 15 rue René Descartes, 67084 Strasbourg, France, ${ }^{4}$ Hybrigenics S.A., F-75014 Paris, France, ${ }^{5}$ current address : University Children's Hospital, Division of Immunology, Steinwiesstrasse 75, CH-8032, Zürich, Switzerland, ${ }^{6}$ current address : CellVir, 4 rue Pierre Fontaine, 9100 Evry, France and ${ }^{7}$ Current Address: Institutes of Life and Health Engineering, Jinan University, 601 Huang Pu Avenue West, Guangzhou 510632, China.

Email: Julie Lemay - julie.lemay@kispi.uzh.ch; Priscilla Maidou-Peindara - maidou-peindara@cochin.inserm.fr; Thomas Bader - thomas.bader@laposte.net; Eric Ennifar - e.ennifar@ibmc.u-strasbg.fr; Jean-Christophe Rain - jcrain@hybrigenics.fr; Richard Benarous* - richard.benarous@inserm.fr; Lang Xia Liu* - langxialiu@gmail.com

* Corresponding authors

Published: 10 June 2008

Retrovirology 2008, 5:47 doi:10.1186/1742-4690-5-47
Received: 9 January 2008

Accepted: 10 June 2008

This article is available from: http://www.retrovirology.com/content/5/l/47

(C) 2008 Lemay et al; licensee BioMed Central Ltd.

This is an Open Access article distributed under the terms of the Creative Commons Attribution License (http://creativecommons.org/licenses/by/2.0), which permits unrestricted use, distribution, and reproduction in any medium, provided the original work is properly cited.

\begin{abstract}
Reverse transcription of the genetic material of human immunodeficiency virus type I (HIV-I) is a critical step in the replication cycle of this virus. This process, catalyzed by reverse transcriptase (RT), is well characterized at the biochemical level. However, in infected cells, reverse transcription occurs in a multiprotein complex - the reverse transcription complex (RTC) - consisting of viral genomic RNA associated with viral proteins (including RT) and, presumably, as yet uncharacterized cellular proteins. Very little is known about the cellular proteins interacting with the RTC, and with reverse transcriptase in particular. We report here that HIV-I reverse transcription is affected by the levels of a nucleocytoplasmic shuttling protein - the RNA-binding protein HuR. A direct protein-protein interaction between RT and HuR was observed in a yeast two-hybrid screen and confirmed in vitro by homogenous time-resolved fluorescence (HTRF). We mapped the domain interacting with HuR to the RNAse $H$ domain of RT, and the binding domain for RT to the Cterminus of HuR, partially overlapping the third RRM RNA-binding domain of HuR. HuR silencing with specific siRNAs greatly impaired early and late steps of reverse transcription, significantly inhibiting HIV-I infection. Moreover, by mutagenesis and immunoprecipitation studies, we could not detect the binding of HuR to the viral RNA. These results suggest that HuR may be involved in and may modulate the reverse transcription reaction of HIV-I, by an as yet unknown mechanism involving a protein-protein interaction with HIV-I RT.
\end{abstract}

\section{Introduction}

HIV-1 reverse transcriptase (RT) is a DNA- and RNAdependent DNA polymerase responsible for converting the virion ssRNA genome into a dsDNA genome once the virus has entered the cell [1]. HIV-1 RT also displays RNA degradation activity (RNase $\mathrm{H}$ ), independent of its polymerase activities. Both activities are essential for the reverse transcription process in vivo.

HIV-1 reverse transcriptase is incorporated into virions, during their assembly, as part of the Gag-Pol precursor. It is processed into two subunits by the viral protease, during 
particle maturation, after budding. The p66 subunit includes domains responsible for the RNase $\mathrm{H}$ and DNA polymerase activities, whereas the p 51 subunit bears only the polymerase domain. The two subunits dimerize within the viral particle, and form the p66/p51 heterodimer, the active form of the enzyme [2]. Reverse transcription occurs essentially in the cytoplasm once the virus has entered the cell. It is mediated by a complex formed by two copies of the viral RNA, associated viral proteins, including RT, and, presumably, cellular proteins that have yet to be characterized. This reverse transcription complex (RTC) is gradually transformed into the preintegration complex (PIC), during its progressive migration to the nucleus. The PIC is responsible for ensuring the integration of the proviral genomic DNA generated by reverse transcription into the host genome (recently reviewed in [3]).

Recent studies point towards the importance of cellular cofactors for an efficient reverse transcription of HIV-1 in vivo $[4,5]$. However, the cellular factors involved in this reaction have not yet been identified. Moreover, there have been very few reports of cellular proteins interacting with HIV-1 RT. Hottiger et al. showed that the HIV-1 p66 monomer interacts directly with beta-actin [6]. Olova et al. have shown that eRF1 interacts directly with the reverse transcriptase of the murine retrovirus, M-MuLV [7], but not with HIV-1 RT. We searched for other molecules potentially interacting with HIV-1 RT, by carrying out yeast twohybrid screening with HIV-1 p66 as the bait and a CEMC7 cell line cDNA library as the prey. We identified HuR (or ELAVL1) as potentially interacting with HIV-1 RT.

HuR is a ubiquitous protein involved essentially in stabilizing mRNAs by binding to adenylate/uridylate-rich elements (AREs). HuR is mostly found in the nucleus, but can shuttle to the cytoplasm, and has also been found associated with stress granules $[8,9]$. There is a direct correlation between the capacity of HuR to stabilize mRNA and its shuttling to the cytoplasm. HuR shuttling can be observed in the HIV cell targets, T lymphocytes, following their activation, by the binding of ICAM-1 to the LFA-1 integrin, for example [10]. Furthermore, HuR levels vary during the cell cycle and are maximal during the G2 phase $[11,12]$.

We show here that HuR interacts with HIV-1 RT in the RNase $\mathrm{H}$ region, and that HuR silencing, using specific siRNAs, or overexpression, through the transient transfection of an HuR expression vector, greatly affects the reverse transcription process.

\section{Materials and methods Yeast two-hybrid screening}

Two-hybrid screens were carried out with a cell-to-cell mating protocol, as previously described [13,14]. Ran- dom cDNA librairies from CEMC7 cells were constructed into the pP6 plasmid derived from the original pACT2, by blunt-end ligation of an SfiI linker. E. coli DH10B (Invitrogen, Carlsbad, California) was transformed with these libraries, giving over 50 million clones. S. cerevisiae was transformed with these libraries, by the classical lithium acetate protocol. Ten million independent colonies were collected, pooled, and stored at $-80^{\circ} \mathrm{C}$ as aliquots of the same library. The HIV-1 reverse transcriptase gene was amplified with appropriate primers from the YU2 proviral DNA plasmid and inserted into pB27 [15]. For the rebound screening, HuR was inserted into pB27, using appropriate primers, and the HIV genomic library used was as previously described $[13,15]$.

\section{Plasmids}

The prokaryotic expression vector, p6H-RT-PR, was kindly provided by Dr Giovanni Maga and has been described elsewhere [16]. GST-HuR was constructed by PCR amplification of the HuR gene from the image clone \# IMGCLO2901220 (accession \# BC003376) bought from GeneService (Cambridge, UK), using the following primers: sense: 5'-GCG GCG GAA TTC TCT AAT GGT TAT GAA GAC CAC A-3', antisense: 5'-GCG GCG GTC GAC TTA TTT GTG GGA CTT GTT GG-3'. The resulting fragment was inserted between the EcoRI and SalI sites of pGEX4T1 (GE healthcare). pCMV-HuR was constructed by introducing this fragment into pcDNA3 (Invitrogen). pNL43AREmut was generated by site-directed mutagenesis on pNL4-3 [17], using the "overlap extension PCR" method with $p f u$ polymerase (Stratagene), as described elsewhere [18]. The following primers were used: sense: 5'-CAC TAC TTC GAC TGC TTC TCC GAG TCT GCT ATA AGA AAT ACC ATA TTA GGA CGT AT-3', antisense: 5'-AGA CTC GGA GAA GCA GTC GAA GTA GTG CAG ATG AAT TAG TTG GTC TGC-3'. The Flag-p66 construct was generated by PCR amplification of the HIV-1 NL4-3 p66 region and its insertion into the pSG5 vector (Stratagene).

\section{Production and purification of recombinant proteins}

$6 x H i s-t a g g e d ~ R T$ was produced from E. coli DH5 $\alpha$ transformed with the p6H-RT-PR expression vector. GST-HuR was produced from E. coli BL21 transformed with pGEX4T1-HuR. Overnight cultures of bacteria were diluted to an OD of 0.05 in LB media $(50 \mu \mathrm{g} / \mathrm{ml}$ ampicillin) and cultured to an OD of 0.4. Then, $1 \mathrm{mM}$ isopropyl1 -thio- $\beta$-D-galactopyranoside (IPTG) was added to the cultures, which were incubated for 3 hours to induce protein production. The His-RT bacterial pellet was weighed and ground for 2 minutes in a chilled mortar with 2.5 parts of type A-5 aluminum oxide (Sigma), at $4^{\circ} \mathrm{C}$. The extract was then resuspended in extraction buffer (300 $\mathrm{mM} \mathrm{NaCl}, 50 \mathrm{mM}$ sodium phosphate) and centrifuged at $12,000 \mathrm{~g}$ for 20 minutes at $4^{\circ} \mathrm{C}$. His-tagged recombinant proteins were purified from the supernatant, using BD- 
TALON IMAC Resin (Clontech), according to the manufacturer's instructions. The GST-HuR bacterial pellet was resuspended in lysis buffer (20 mM Tris-Cl pH 7.5, $2 \mathrm{mM}$ DTT, $1 \mathrm{mM}$ EDTA, $10 \%$ glycerol, $1 \mathrm{M} \mathrm{NaCl}, 1 \mu \mathrm{g} / \mathrm{ml}$ lysosyme, $100 \mu \mathrm{g} / \mathrm{ml}$ chloramphenicol, $0.1 \mathrm{mM}$ PMSF) supplemented with protease inhibitor cocktail (Sigma), and subjected to 315 -second sonication pulses, on ice. The lysate was centrifuged for 30 minutes, at 15,700 g and $4^{\circ} \mathrm{C}$. The supernatant was incubated with GlutathioneSepharose 4B beads (GE Healthcare) for 1 hour at $4^{\circ} \mathrm{C}$. The beads were washed several times in lysis buffer and proteins were eluted in $20 \mathrm{mM}$ reduced glutathione (Roche).

\section{HTRF assay}

GST-HuR or GST was serially diluted in the following buffer: $50 \mathrm{mM}$ phosphate buffer, $0.8 \mathrm{M}$ potassium phosphate, $0.0075 \%$ Tween-20 and $2 \mathrm{mM} \mathrm{MgCl} 2$. RT-His was diluted in the same buffer such that the final reaction mixture contained $10 \mathrm{ng} / \mathrm{ml}$. Anti-GST-TBPEu ${ }^{3+}$ and antiHisXL665 antibodies were reconstituted as recommended by the manufacturer. The proteins were incubated with both antibodies and readings were taken in a black 384 half-well plate (Greiner). The plate was read with the PHERAstar apparatus from BMG LABTEC at $665 \mathrm{~nm}$ (XL665 fluorescence) and $620 \mathrm{~nm}$ (europium cryptate fluorescence) after excitation at $337 \mathrm{~nm}$. This dual measurement made it possible to calculate the signal ratio. The specific signal was obtained as follows:

Fluorescence ratio $\mathrm{R}=$ [signal $665 \mathrm{~nm} /$ signal $620 \mathrm{~nm}] \times$ $10,000 . \Delta \mathrm{R}=\left[\mathrm{R}_{\text {sample }}-\mathrm{R}_{\text {negative }}\right]$ and $\Delta \mathrm{F}(\%)=\left[\Delta \mathrm{R} / \mathrm{R}_{\text {negative }}\right]$ $\times 100$.

\section{Cells, viruses, and transfections}

HEK293T, HeLa, HeLa P4.2 and HeLa R7 Neo cells were grown in DMEM (Invitrogen) supplemented with $10 \%$ fetal calf serum (FCS; Invitrogen) and antibiotics (100 units $/ \mathrm{ml}$ penicillin, $100 \mathrm{mg} / \mathrm{ml}$ streptomycin; Invitrogen). HeLa P4.2 (CD4+, LTR-LacZ) cells were cultured in the presence of $200 \mu \mathrm{g} / \mathrm{ml} \mathrm{G} 418$ [19]. HeLa R7 Neo (stably infected with the HIV-1 neo $\Delta e n v$ virus) cells were cultured in the presence of $500 \mu \mathrm{g} / \mathrm{ml} \mathrm{G} 418$, and were kindly provided by Dr. Pierre Sonigo [20]. Jurkat cells were grown in RPMI 1640 (Invitrogen), supplemented with 10\% FCS and antibiotics (100 units/ml penicillin, $100 \mathrm{mg} / \mathrm{ml}$ streptomycin). For the overexpression and immunofluorescence assays, HeLa cells were tranfected with Fugene-6 reagent (Roche), according to the manufacturer's protocol. Virus stocks were generated by transfecting HEK293T cells with the provirus pNL4-3 or pNL4-3AREmut, using the calcium phosphate technique (Stratagene). Single round pseudotyped viruses were obtained by cotransfecting cells with pNL4-3Aenv and a VSV-G envelope expression vector, as previously described [21]. Viral particle production in the cell culture supernatant was evaluated with the anti-p24 ELISA kit from Beckman Coulter. Purified viral particles were obtained by passing the cell culture supernatant through a filter with $0.45 \mu \mathrm{M}$ pores, and centrifuging the filtrate on a $20 \%$ sucrose cushion at $27,000 \mathrm{rpm}$ for 90 minutes at $4{ }^{\circ} \mathrm{C}$ in an SW28 rotor. For infected cell quantification, HeLa P4.2 cells were fixed in $0.5 \%$ glutaraldehyde (Sigma) in phosphate-buffered saline (PBS) and stained overnight at $4{ }^{\circ} \mathrm{C}$ in $4 \mathrm{mM}$ potassium ferrocyanide, $4 \mathrm{mM}$ potassium ferricyanide, $2 \mathrm{mM}$ $\mathrm{MgCl}_{2}$ and $400 \mu \mathrm{g} / \mathrm{ml} \mathrm{X-Gal} \mathrm{(Roche)} \mathrm{in} \mathrm{PBS.}$

\section{siRNA assays}

siRNA HuR1 (HuR1.1: GCCUGUUCAGCAGCAUUGGTT and HuR1.2: CCAAUGCUGCUGAACAGGCTT) was synthesized by Eurogentec and annealed according to the manufacturer's instructions. siRNA HuR2 and HuR3 were obtained from Qiagen (cat.no. SI00300139 and SI03246887 respectively). The negative control, a non targeting siRNA (siCONTROL) was obtained from Dharmacon. HeLa or HeLa P4.2 cells were transfected twice with $30 \mathrm{nM}$ of siRNA, using Oligofectamine reagent (Invitrogen).

\section{Quantification of early and late RT products in infected HeLa cells}

HeLa cells were transfected either twice with $30 \mathrm{nM}$ siHuR1 (or siCtrl) siRNA during a 24-hour period, using Oligofectamine reagent (Invitrogen), or with $1 \mu \mathrm{g} / \mathrm{mL}$ pCMV-HuR (or the empty vector), using FUGENE-6 (Roche Applied Science). Cells were incubated for 24 hours and then washed three times with PBS and infected with NL4.3( $\Delta$ Env) VSV-G-pseudotyped virus at a multiplicity of infection (MOI) of 0.1. About 16 hours after infection, cells were harvested, washed in PBS and treated with 500 units of DNase I (Roche Diagnostics) for $1 \mathrm{~h}$ at $37^{\circ} \mathrm{C}$. Total DNA was then extracted, using a QIAamp blood DNA minikit (Qiagen), and early and late RT products (minus-strand stop DNA and full-length DNA, respectively) were quantified by real-time PCR. DNA samples were assayed in duplicate, using the LC FastStart DNA hybridization probes kit (Roche Diagnostics). Fluorescence was measured on a LightCycler ${ }^{\circledast} 2.0$ Instrument (Roche Applied Science). The following primers and probes were used: early RT forward primer: 5'-TAACTAGGGAACCCACTG-3'; early RT reverse primer: 5'-CACTGACTAAAAGGGTCT-3'; early RT probe1: GCTTGCCTTGAGTGCTCA (Fluo); early RT probe2: (Red640) GTAGTGTGTGCCCGTCT (Phosphate); late RT forward primer: 5'-CGTCTGTTGTGTGACT-3'; late RT reverse primer: 5'-TTTTGGCGTACTCACC-3'; late RT probe1: ATCTCTCGACGCAGGAC (Fluo); late RT probe2: (Red640) GGCTTGCTGAAGCGCG (Phosphate). DNA copy numbers were determined from standard curves obtained using DNA samples extracted from HeLa R7 Neo 
cells, which were estimated to contain $1.24 \pm 0.03$ copies of proviral cDNA per cell [20]. Results were normalized by dividing by the number of cells, using the Light Cycler control kit according to the manufacturer's instructions (Roche Diagnostics).

\section{Western blot analysis}

Cells were lysed in lysis buffer (20 mM Tris pH 7.5, 50 $\mathrm{mM} \mathrm{NaCl}, 2 \mathrm{mM}$ EDTA, 1\% Triton X-100). The protein concentration of the extract was determined by Bradford assay, using the Coomassie Protein Assay Reagent (Pierce). Equal amounts of protein were loaded into each well of a polyacrylamide gel, subjected to SDS-PAGE and transferred to PVDF membranes for immunoblotting. Membranes were exposed to X-ray films or revealed by the Fuji LAS-3000 video acquisition device.

\section{Antibodies}

Anti-GST-TBPEu ${ }^{3+}$ and anti-HisXL665 antibodies were purchased from Cisbio Intl. Rabbit anti-HuR antibody was obtained from Upstate. Goat anti-actin, mouse monoclonal anti-HuR and rabbit anti-His antibodies were obtained from Santa Cruz Biotechnology. Rabbit polyclonal anti-p24, mouse monoclonal EVA3019 anti-HIV-1 RT and rabbit anti-HIV-1 p24 antibodies were obtained from the NIBSC Centralised Facility for AIDS Reagents supported by the EU program EVA/MRC (contract QLKZ-CT1999-00609) and the UK Medical Research Council, and were kindly provided by Dr D. Helland and Dr A.M. Szilvay (anti-RT) and Dr G Reid (anti-p24). Mouse monoclonal anti-FLAG M2, rabbit polyclonal anti-FLAG, and mouse monoclonal anti-HA antibodies were obtained from Sigma. Horseradish peroxidase (HRP)-coupled antimouse, anti-rabbit and anti-goat secondary antibodies were obtained from Dako. Fluorescent secondary antibodies directed against rabbit FITC, rabbit Cy3, mouse FITC and mouse Cy3 were obtained from Jackson ImmunoResearch.

\section{Computational analysis}

ARE-containing mRNA sequences were aligned, using the AlignX program of VectorNTI AdvanceTM software (Invitrogen). RNA secondary structures were determined, using the MFOLD program [22]. Accelrys Discovery Studio software was used to visualise the binding site of HuR on the RT heterodimer (PDB 1D 1HMI). Quantitative analysis of the siRNA silencing of HuR by Western blot was done with the Multi-Gauge software associated with the Fuji LAS-3000 video acquisition device.

\section{Immunoprecipitation assays}

The protocol used to detect mRNAs bound to HuR has been described elsewhere $[23,24]$. HeLa cells $\left(10^{6}\right.$ cells) were lysed in a lysis buffer (50 mM Tris pH 7.5; $150 \mathrm{mM}$ $\mathrm{NaCl}, 1 \%$ Nonidet $\mathrm{P} 40,0.5 \%$ sodium deoxycholate). The supernatant was precleared with $2 \mu$ g of IgG1 (Santa Cruz Biotechnology) and $50 \mu \mathrm{l}$ of protein G-agarose (Roche). The cleared supernatant was then incubated with $2 \mu \mathrm{g}$ of mouse anti-HuR or mouse anti-HA antibody for 1 hour at $4^{\circ} \mathrm{C}$. We then added $50 \mu \mathrm{l}$ of protein G-agarose and incubated the mixture overnight at $4^{\circ} \mathrm{C}$. Beads were washed five times in lysis buffer and treated with RNase-free DNaseI and proteinase K. RNA was extracted with phenol/ chloroform, precipitated, and reverse-transcribed using MLV RT and random primers (Invitrogen). Precipitated mRNA was detected by qPCR, using the protocol and primers described by Lal et al. [23]. The primers used to detect Gag-Pol mRNA were the same as those used to detect the full-length HIV cDNA (late RT product).

\section{Results \\ HuR is a cellular protein interacting with HIV-I p66 reverse transcriptase}

We used a yeast two-hybrid screening system to identify cellular proteins able to interact with HIV-1 p66 reverse transcriptase. HIV-1 p66 fused to the LexA binding domain (LexA BD) was used as a bait to screen random primed cDNA libraries of CEMC7 lymphocytes, fused to the Gal4 activator domain. HuR fragments interacting with p66 HIV-1 RT were identified. All the fragments obtained contained the region of HuR between amino acids 286 and 326, which overlaps the third RNA recognition motif (RRM) in the C-terminal region of HuR (fig. 1A). This region constitutes the binding site of HIV-1 RT on HuR.

We assessed the specificity of HuR interaction with HIV-1 RT and mapped the HuR binding site on HIV-1 RT, by carrying out a yeast two-hybrid rebound screening, using HuR fused to LexA BD as the bait and a library of random fragments of HIV-1 DNA as the prey. This library of random HIV-1 DNA fragments was obtained from DNA sheared by nebulization, and then repaired and fused to Gal4 AD, as previously described [25]. All the random fragments of HIV-1 DNA that interacted with $\mathrm{HuR}$ included part of the RT sequence - the RNAse $\mathrm{H}$ region, in particular (Fig. 1B). No HIV-1 fragment interacting with HuR was found outside the RT sequence. The results of this rebound screen confirmed the specificity of the interaction between the two proteins, and allowed us to map the site of interaction with HuR between amino acids 482 and 539 in the C-terminal region of p66, corresponding to the domain with RNase $\mathrm{H}$ activity (fig. 1B).

Mapping of the predicted binding site for HuR on the RT heterodimer bound to a primer-template DNA revealed that it is freely accessible and extends to the vicinity of the primer-template. This observation leaves open the possibility of a simultaneous interaction of HuR with both RT and viral RNA (fig 1C). 
A.

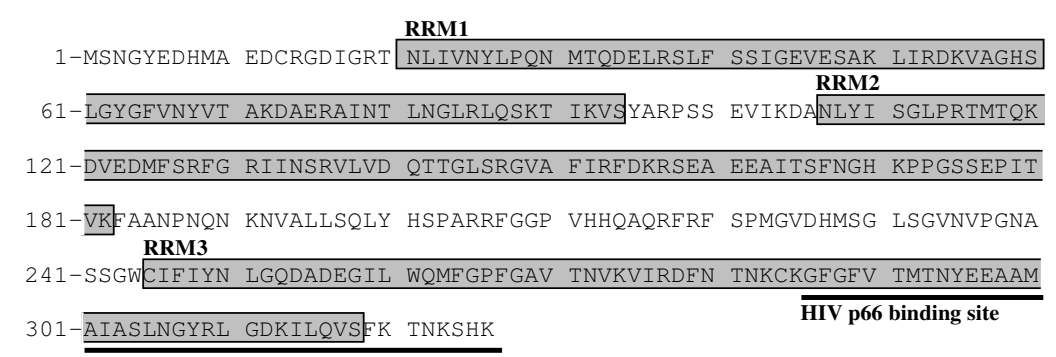

B.

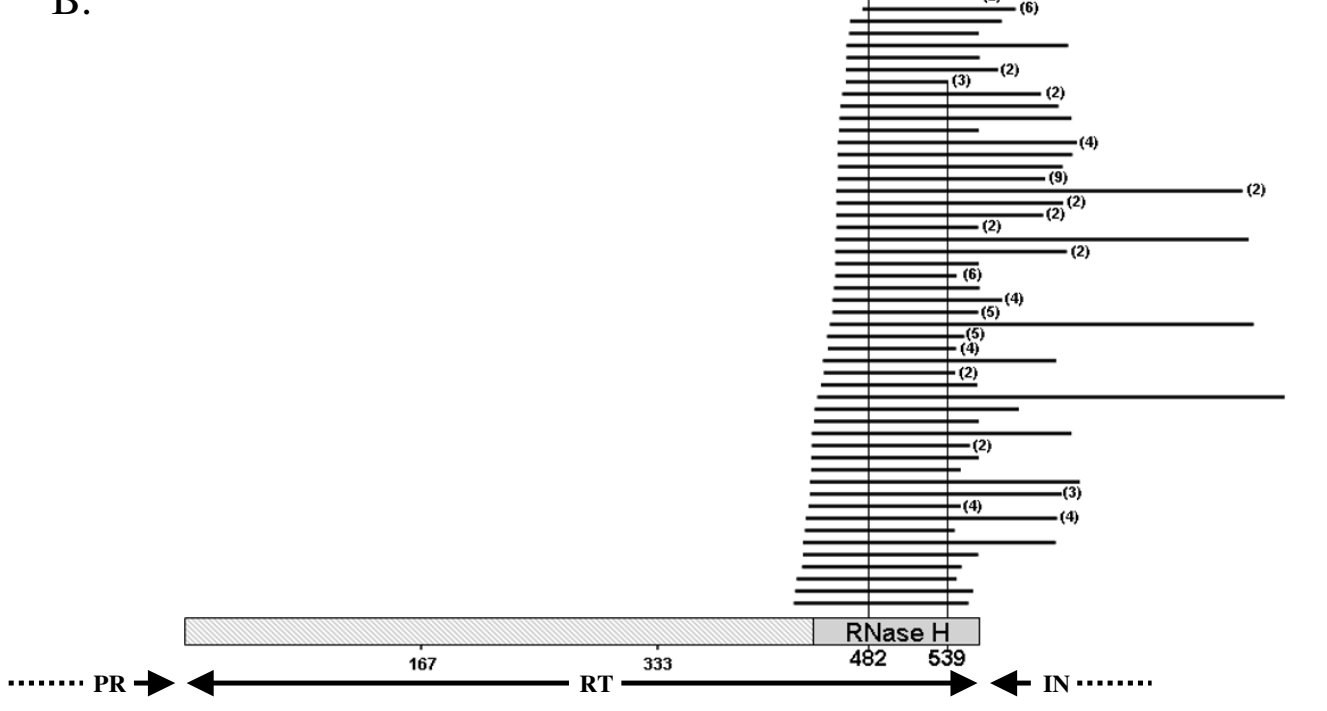

C.
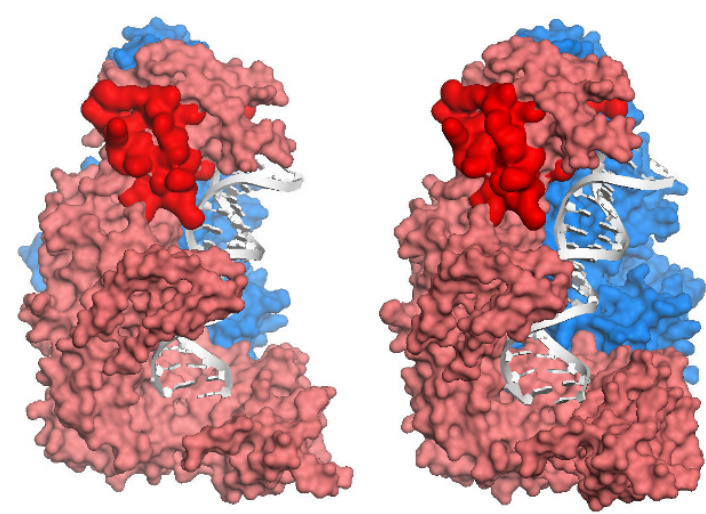

Figure I

Identification of HuR as a partner of HIV-I p66 reverse transcriptase. A. A yeast two-hybrid screen was carried out with HIV-I RT-p66 as the bait, and a CEMC7 CDNA library as the prey. Amino-acid sequence of HuR and its predicted binding site to HIV-I p66. RRM: RNA recognition motif. B. Alignment of the different fragments of HIV-I interacting with HuR in the yeast two-hybrid rebound screen, using HuR as the bait and random fragments of HIV-I YU-2 isolate as the prey. Numbers in brackets indicate the occurrence of each fragment. C. Mapping of the HuR interaction site on HIV-I RT bound to a primertemplate. Solvent accessible surface (probe radius I.4 A) of the protein is represented in two different views (PDB ID IHMI) [53]. The $p 5 I$ is shown in blue and $p 66$ in pink. The DNA primer-template is represented in grey. The putative HuR binding site on $p 66$ is represented in red. 
A.

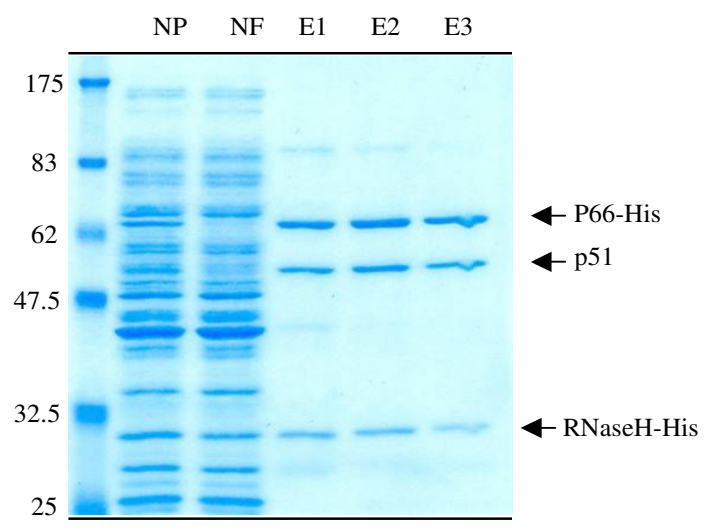

B.

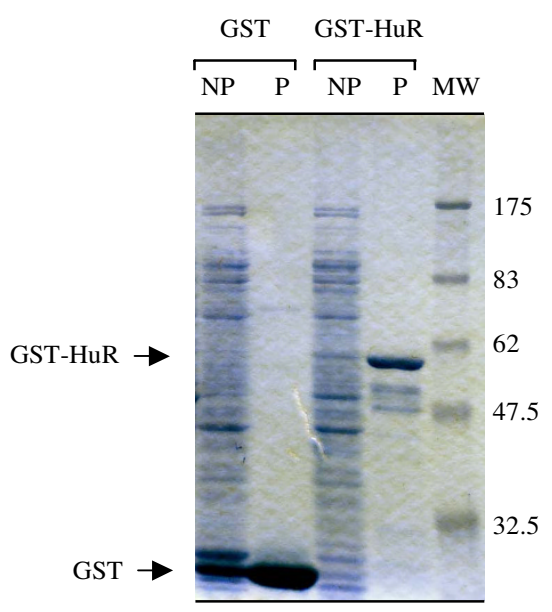

C.

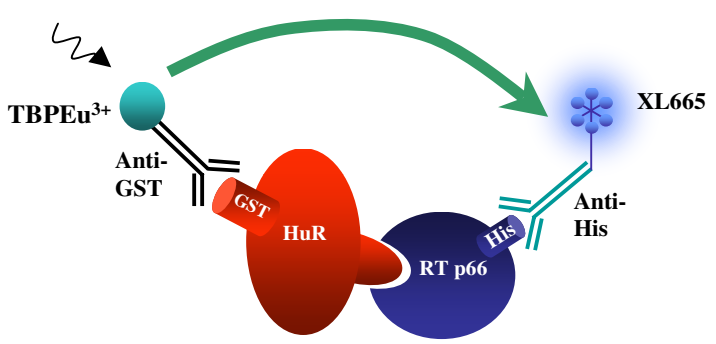

D.

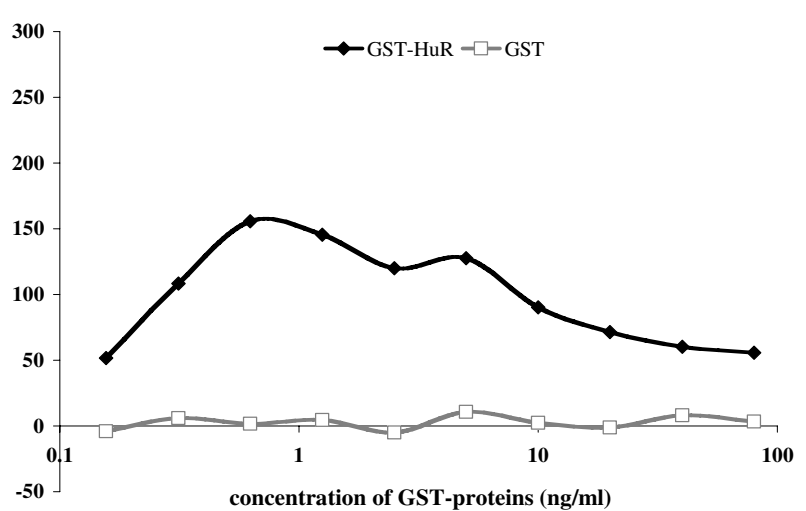

\section{Figure 2}

The HIV-I RT heterodimer interacts directly with GST-HuR. A. Coomassie blue staining of the purified RT heterodimer. NP: non purified, NF: non fixed, EI-E3: elutions. B. Coomassie blue staining of the purified GST and GST-HuR. NP: non purified, P: purified. C. Schematic representation of our HTRF assay (adapted from Cisbio Intl.). Europium trisbipyridine cryptate $\left(\right.$ TBPEu $^{3+}$ ) was coupled to anti-GST antibodies, acting as the FRET energy donor, following excitation at $337 \mathrm{~nm}$. Cross-linked allophycocyanin (XL665) was coupled to anti-His antibodies acting as the FRET energy acceptor and emitting a sustained signal at $665 \mathrm{~nm}$. D. Serial dilutions of purified GST-HuR or GST alone were incubated with a constant concentration of RT-His (10 ng/ml), in the presence of constant amounts of anti-His-XL665 and anti-GST-TBPEu ${ }^{3+}$ antibodies. The Fret signal was measured after 24 hours of incubation at $4^{\circ} \mathrm{C}$. These results are representative of those obtained in four independent experiments. 


\section{Purified GST-HuR and HIV-I reverse transcriptase interact} together in an in vitro assay

We produced and purified the recombinant proteins, to confirm the interaction between the two predicted partners in vitro. We used p6H-RT-PR, a vector allowing the simultaneous production of a C-ter $6 \mathrm{xHis}$-tagged form of HIV-1 p66 reverse transcriptase together with the HIV-1 protease [16]. The products of C-ter 6xHis-tagged p66 cleavage by HIV-1 protease are untagged p51 and C-ter $6 x$ His-tagged RNaseH. The simultaneous production of cleaved and uncleaved p 66 favors the formation of a well folded, fully functional p66/p51 RT heterodimer. Purified $6 \mathrm{xHis}$-proteins were separated by reducing SDS-PAGE and stained with Coomassie blue to assess their purity (fig. 2A). Recombinant RT production was also checked by western blotting (data not shown). As expected, anti-RT monoclonal antibodies detected both RT chains, whereas anti-6xHis antibodies recognized only p66. As the affinity between p66 and p51 is strong, the detection of the p51 chain by Coomassie blue staining results from its coprecipitation with purified p66-His, rather than its binding to the affinity beads.

We also inserted the HuR gene into pGEX4T1, to produce a GST-HuR fusion protein. Purified GST-proteins were separated by SDS-gel electrophoresis and stained with Coomassie blue, to assess their purity (fig. 2B).

The purified recombinant p66-His and GST-HuR proteins were used in an HTRF interaction assay (reviewed in $[26,27])$. A schematic representation of the principle underlying this assay is shown in figure 2C. GST-HuR and C-ter 6xHis tagged RT-p66 are incubated with anti-GST antibodies conjugated with a fluorescence energy donor TBPEu3+, and anti-6His antibodies conjugated with a fluorescence energy acceptor XL665. Upon TBPEu ${ }^{3+}$ excitation at $337 \mathrm{~nm}$, a fluorescence resonance energy transfer signal emitted at $665 \mathrm{~nm}$ by the XL665 conjugate can be detected if an interaction occurs between the two recombinant proteins. The magnitude of this signal depends on the respective concentrations of the two interacting proteins.

Serial dilutions of the purified GST-HuR or GST alone were incubated for 24 hours at $4^{\circ} \mathrm{C}$ in the presence of constant amounts of antibodies against the 6xHis and GST tags, and a constant concentration of RT-His $(20 \mathrm{ng} / \mathrm{ml}$ in total present in the reaction mixture, corresponding to about $10 \mathrm{ng} / \mathrm{ml}$ of p66-His, as evaluated by densitometry). As expected, a bell-shaped curve was obtained (fig. 2D). At lower concentrations, too little GST-HuR was present in the complex with RT-His and, at higher concentrations, some of the anti-GST antibodies were captured by the excess GST-HuR not associated with RT-His, thereby diminishing the signal. We obtained a signal with
GST-HuR, but not with GST alone, consistent with a specific interaction. The two peaks obtained may result from the interaction of GST-HuR with both the full-length C-ter 6xHis p66 and the C-ter 6xHis $\mathrm{RNaseH}$ copurified on IMAC resin (fig. 2A). These results confirm that the RTp66 and HuR recombinant proteins can interact in vitro and that this interaction is specific, as it does not take place with GST alone used as a control.

\section{HuR is important for the early steps of the HIV-I replication cycle}

We evaluated the potential role of HuR in the HIV-1 replication cycle, using RNA interference techniques for gene silencing. We first monitored the early steps of the viral replication cycle, using an assay dependent on the correct entry, reverse transcription and integration of HIV into the cell genome. Reporter HeLa P4.2 cells (CD4+, LTR-LacZ, endogenous CXCR4) were independently transfected with three different siRNAs targeting different regions of the HuR mRNA, a negative control siRNA or no siRNA. Three days later, cells were infected with the $\mathrm{X} 4$ tropic strain HIV $-1_{\text {NL4.3. }}$. An aliquot of the transfected cells was lysed at the time of infection and HuR silencing was assessed by western blotting (fig. 3A, upper panel). A 90\% decrease in HuR levels was observed. Cells were fixed 24 hours after infection, and stained with X-Gal, as previously described [19]. An aliquot of cells was collected, lysed and analyzed by western blotting. HuR knockdown was maintained throughout the experiment, as $90 \%$ silencing of HuR was still observed at the time of fixation (fig. 3A, lower panel). Tat-activated LTR was used for $\beta$-galactosidase production and the counting of successfully infected cells (fig. 3B). These results show significant impairment of the infection of HeLa P4.2 cells treated with the three different siRNAs. The similar levels of downregulation obtained with all three siRNAs, despite differences in the regions of the HuR mRNA targeted, and the similar phenotypic effects of these three siRNAs in our assay suggest that HuR may be involved in the early steps of the HIV-1 replication cycle.

We further assessed the importance of HuR in the early steps of HIV infection, by studying the reverse transcription products generated in infected cells in the presence and absence of HuR. We transfected HeLa cells with siRNA HuR1 or a control siRNA and infected them 48 hours later with non-replicative HIV-1 $\Delta$ Env-luciferase VSV-G pseudotyped viruses. The viral DNA produced by reverse transcriptase during this single cycle of infection were quantified by quantitative real-time PCR, using primers specific for early products (minus-strand, strong stop DNA) or late products (full-length DNA), as described in Materials and Methods. In cells treated with the HuR1 siRNA, the levels of both transcription products were much lower than those in cells treated with the control siRNA (fig. 3C). We also investigated the effects on 


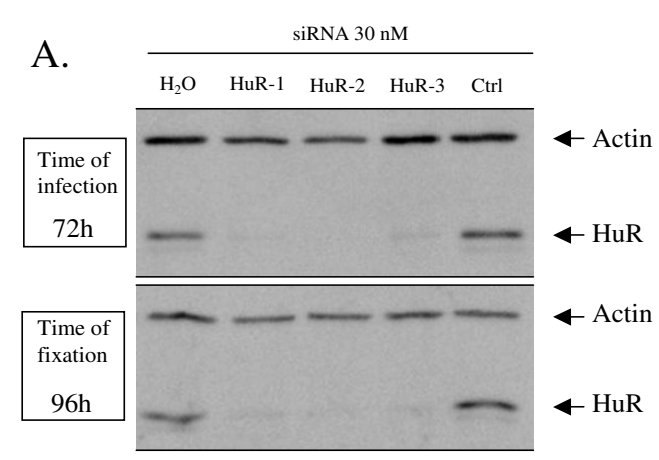

B. D1:siRNA D2:siRNA D4:infection D5:staining

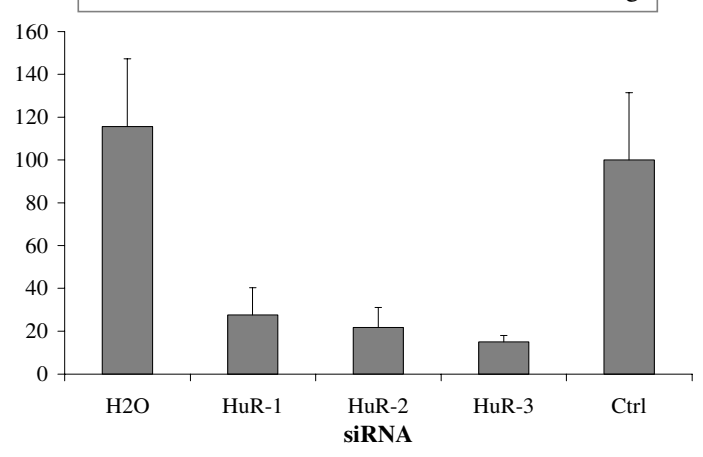

C.

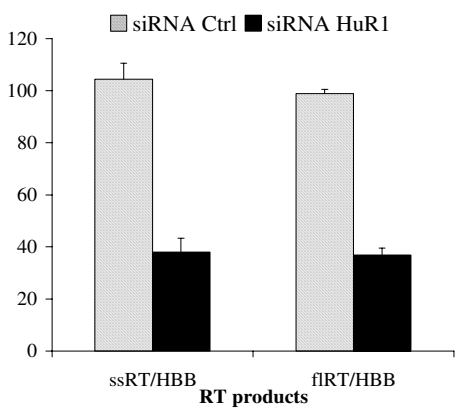

D.

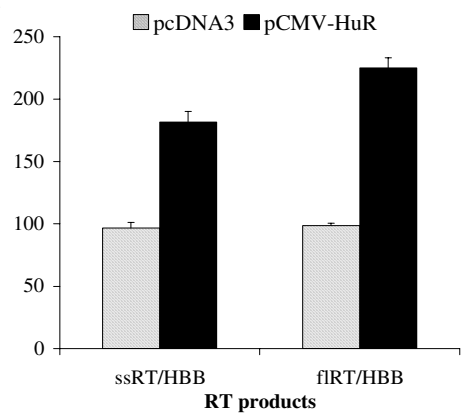

\section{Figure 3}

HuR is involved in the early steps of HIV-I replication cycle. A. siRNA silencing of HuR revealed by Western blot. HeLa P4.2 cells (CD4+ , LTR-LacZ) were transfected with $30 \mathrm{nM}$ of siRNAs directed against HuR $(\mathrm{HuRI}, \mathrm{HuR2}, \mathrm{HuR} 3), \mathrm{H}_{2} \mathrm{O}$, or a non targeting siRNA (Ctrl). For each siRNA, five wells were infected with the HIV-I ${ }_{N L 4.3}$ strain, 72 hours after transfection with the siRNA. The contents of one well were collected and lysed, to check that HuR expression was silenced at the time of infection (A, upper panel). B. Effect of HuR silencing on the infection of cells by wild type HIV-I. 24 hours post-infection, infected cells were counted after the fixation and X-Gal staining of triplicate wells. The contents of one well were collected and lysed, to check that HuR expression was effectively silenced at the time of fixation (A, lower panel). The results presented are a compilation of six independent experiments, normalized as a function of the results obtained with the control siRNA (Ctrl). C. Effect of HuR silencing on HIV-I reverse transcription. HeLa cells were treated with siRNA HuR-I or a non targeting siRNA (Ctrl), then infected with HIV-I $\Delta$ Env-luciferase VSV-G pseudotyped viruses at an MOI of I. Total DNA was extracted from the infected cells and RT products were quantified by quantitative real-time PCR, 16 hours after infection. ssRT: minus-strand strong stop DNA, fIRT: full-length HIV DNA, HBB, human beta-globin. D. Effect of HuR overexpression on HIV-I reverse transcription. As in C, except that the cells were transfected with a vector allowing HuR overexpression (pCMV-HuR) or an empty vector (pcDNA3), before infection. 
reverse transcription of increasing HuR levels, by transfection with a vector allowing the overexpression of HuR (pCMV-HuR). In the presence of HuR overproduction, by contrast with what was observed with HuR silencing, both early and late products of reverse transcription were more abundant than in mock-transfected cells (fig. 3D). These results suggest a potential role for $\mathrm{HuR}$ in reverse transcription.

\section{HuR is not required for the post-integration steps of the HIV-I replication cycle}

As the RNAse $\mathrm{H}$ domain found in our yeast two-hybrid screens is also a part of the Gag-Pol precursor, we investigated whether HuR also affected other steps of the viral replication cycle. We analyzed the impact of knocking down HuR levels in the producer cells. HeLa cells were treated with siRNA HuR1 or control siRNA. The cells were then transfected with the pNL4.3 provirus, making it possible to bypass the reverse transcription step. The silencing of HuR 48 hours after transfection with the HuR1 siRNA was assessed by western blotting (fig. 4A). No difference in virus production was detected between cells expressing and not expressing $\mathrm{HuR}$, as identified by ELISA quantification of the Gag CA-p24 antigen in the supernatant (fig. 4B). We investigated whether HuR affected the infectivity of the viral particles, by using the supernatant of the cells in fig. 4B to infect HeLa P4.2 cells. No significant difference was observed in the number of infected cells (= infectious particles) (fig. 4C) or in the infectivity of these particles normalized on the basis of equal amounts of released p24 (data not shown). This result is consistent with the lack of detection of any HuR incorporated into viral particles produced from cells producing normal amounts of HuR (fig. 4D). Thus, HuR is unlikely to play a role in the late steps of the HIV-1 replication cycle, such as viral protein production, budding and maturation. Instead, it seems to act only in the target cell, following viral entry.

\section{Mutagenesis of a putative ARE sequence found in the HIV- I genome}

HuR has been reported to interact with ARE sequences found in the RNAs of several distantly related viruses, and is thought to be involved in their stabilization or expression [28-32]. We therefore investigated whether a similar phenomenon was also observed with HIV. We investigated in more detail the possible effects of HuR on the reverse transcription process, taking into account that HuR is generally considered to stabilize ARE-containing mRNAs, by checking HIV-1 RNAs for the presence of such ARE elements. Alignment analysis identified a sequence in HIV-1 $1_{\text {NL4.3 }}$ displaying significant similarity to known ARE sequences, and particularly to that of the prothymosin alpha (PTMA) mRNA (data not shown). An identical "hairpin" structure was predicted for both sequences (data not shown) [24]. The putative HIV-1 ARE sequence is situated in the coding sequence of $v$ if and is remarkably conserved between HIV-1 isolates.

To verify the importance of this putative HIV-1 ARE sequence, we inserted several silent mutations into the coding sequence of pNL4.3, to deplete this region of $U$ residues without affecting the amino acid sequence of vif (fig. 5A). HEK293T cells were transfected with this viral construct, to produce the mutated virus (AREmut). This virus was produced in similar amounts to the WT, although the viral particles were slightly less infectious (figure 5B). This mutated virus was used to infect Jurkat cells, and virus production was followed over time by quantifying HIV Gag CA-p24 antigen in the cell culture supernatant. No significant difference was observed between the replication kinetics of the WT and AREmut viruses (fig. 5C). These results are consistent with an absence of a role for the ARE motif or even with the presence of such a motif in this Vif sequence region of the HIV1 RNA, although we cannot rule out the possibility that such a motif is present elsewhere in the HIV-1 genome.

\section{The role of HuR in HIV-I reverse transcription does not seem to be mediated by binding to the HIV-I RNA}

We investigated whether HuR bound to a non typical class III ARE sequence elsewhere in the HIV-1 RNA, as for c-Jun [33], by determining the possible association of any HIV1 RNA transcript with HuR, in an RNA-immunoprecipitation experiment using anti-HuR antibodies, as previously described [23]. We used HeLa R7 Neo cells stably infected with the HIV-1 neo $\Delta e n v$ virus [20], constituting a homogeneous population with similar levels of HIV-1 transcripts. RNA-immunoprecipitation experiments were carried out with anti-HuR antibodies or irrelevant anti-HA antibodies as the negative control. The immunoprecipitated proteins were detected by western blotting, showing the specific immunoprecipitation of HuR with anti-HuR antibodies and not with anti-HA antibodies (fig. 5D). As a positive control, PTMA mRNA, which is known to bind to $\mathrm{HuR}[23,24]$, was found associated with the immunoprecipitated HuR protein, as revealed by RT-PCR with the anti-HuR immunoprecipitate, using primers specific for PTMA mRNA (fig. 5E). The association of PTMA mRNA with $\mathrm{HuR}$ was specific, as the irrelevant immunoprecipitate obtained with anti-HA antibodies was not enriched in this RNA. The PTMA mRNAs precipitated with the antiHuR antibody were 3.5 times more abundant than the negative control, the mRNA of the housekeeping gene gapdh. In contrast, the HIV-1 Gag-Pol transcript was not greatly enriched compared to PTMA mRNAs, since only a 1.5 folds increase was observed. This difference could be due to the relative abundance of the two mRNA species as well as a difference in the affinity of the interaction between HuR and the different mRNAs. 
A. $\quad$ B.

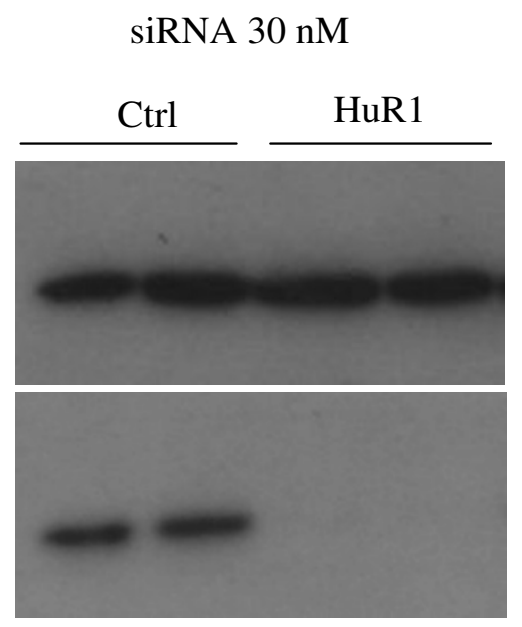

Actin

HuR

\section{C.}

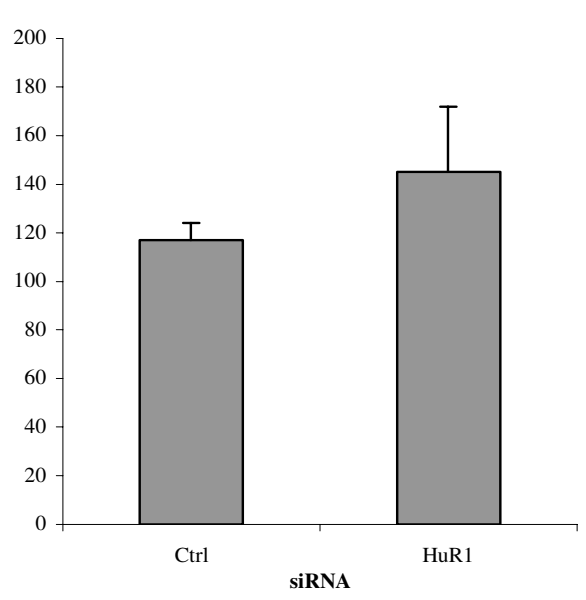

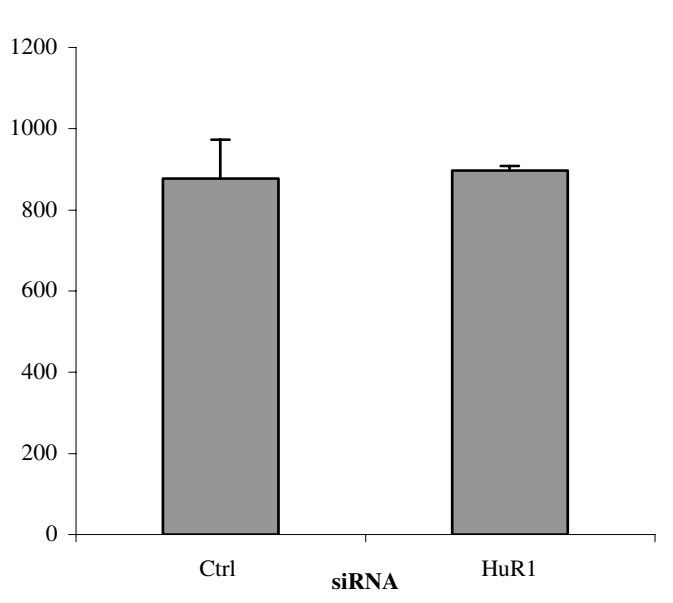

D.

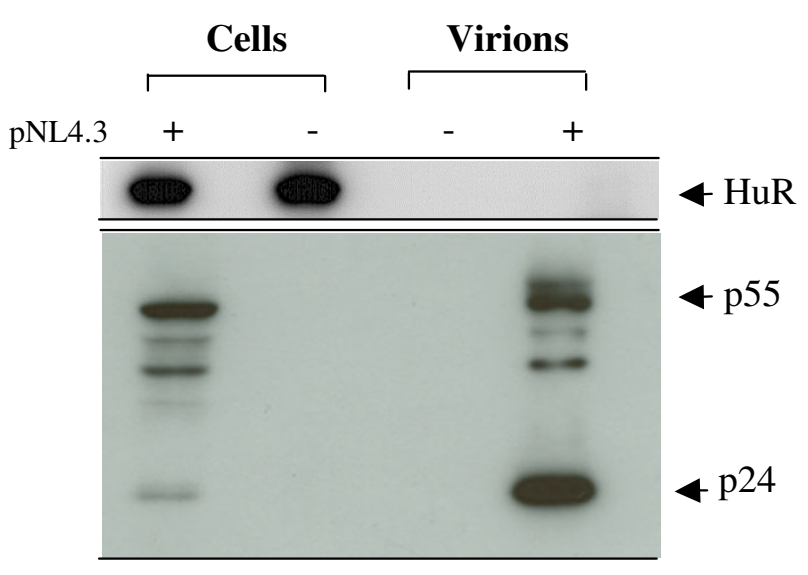

\section{Figure 4}

HuR is not involved in the late steps of the HIV-I replication cycle. HeLa cells were transfected with an siRNA directed against HuR or a non-targeting siRNA (Ctrl). 24 hrs later, cells were transfected with HIV-I provirus pNL4.3. A. Western blot confirming the silencing of HuR 48 hours after transfection with the siRNA. B. Quantification, by ELISA for Gag CA-p24 antigen, of the virions produced in the supernatant, 30 hours after transfection with pNL4.3. C. The virions produced in B were used to infect HeLa P4.2 cells (CD4+, LTR-LacZ). 24 hours post-infection, infected cells were fixed, stained with XGal and counted. D. $2 \times 10^{6}$ HEK293T cells were transfected with HIV-I provirus pNL4.3. 48 hours later, the cell culture supernatant was collected, filtered and ultracentrifuged to collect the virions. Producer cells and virion pellets were lysed and analyzed by western blotting, to check their contents and HuR incorporation. 
A. HIV-1 NL4-3 genome

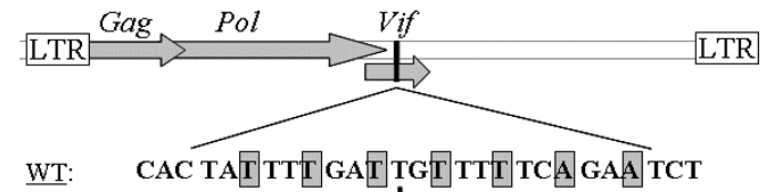

WT:

B.

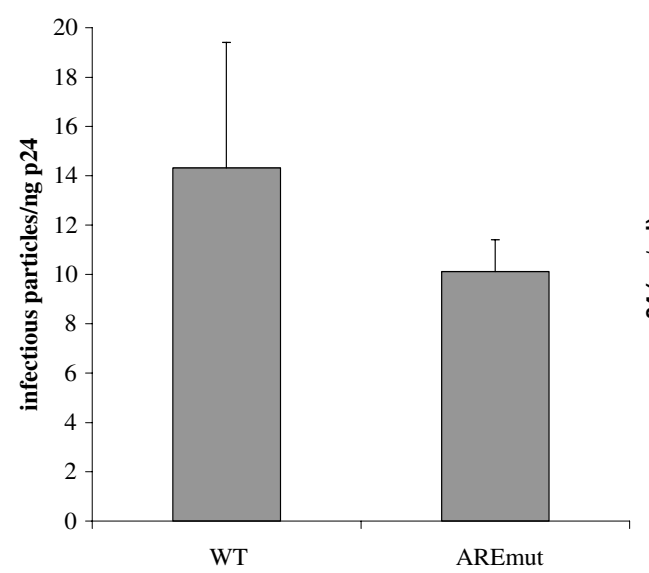

D.

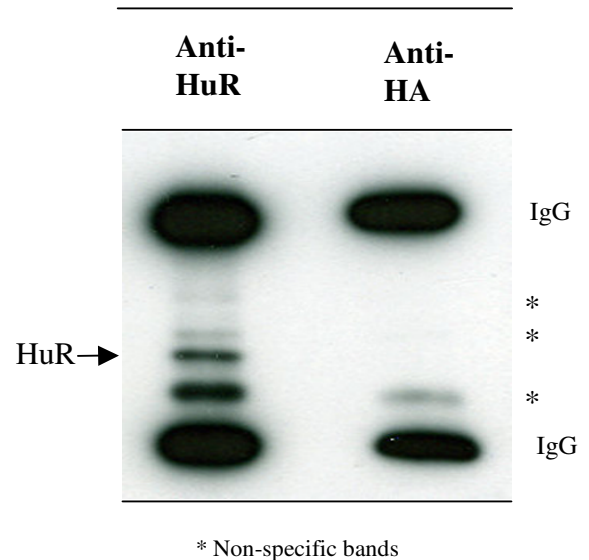

C.

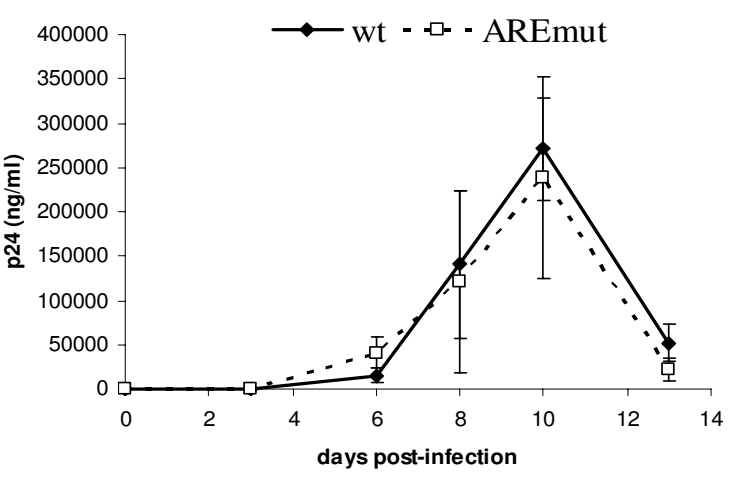

E.

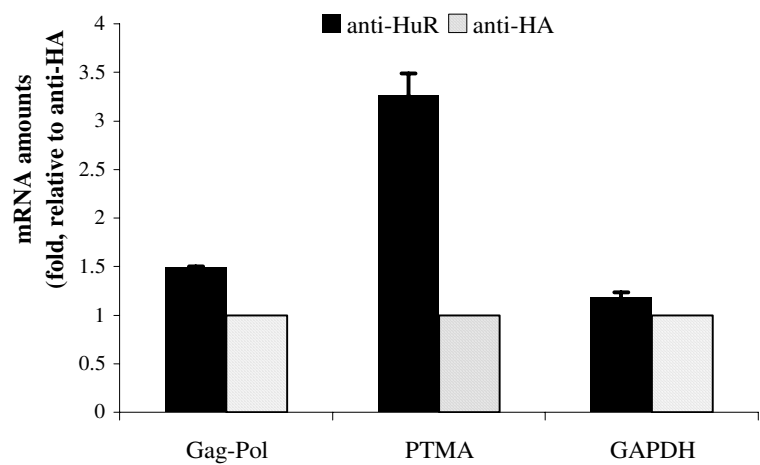

\section{Figure 5}

HuR does not seem to bind to HIV-I RNA. A. Sequence of HIV WT ARE sequence and silent mutations introduced in the AREmut virus. B. HEK293T cells were transfected with WT or AREmut PNL4.3 proviruses. Quantification, by ELISA, of the virions produced in the cell culture supernatant, based on the detection of Gag CA-p24. C. Jurkat cells were infected with WT or AREmut NL4.3 viruses. Viral replication was monitored by ELISA quantification of HIV Gag CA-p24 antigen in the cell culture supernatant. D. Immunoprecipitation was carried out with anti-HuR antibodies or unrelated anti-HA antibodies. Western blot analysis, showing the immunoprecipitated protein. E. Coimmunoprecipitated mRNAs were detected by quantitative RT-PCR, using primers against HIV-I gag-pol, ptma (as a positive control for HuR binding), and the housekeeping gene gapdh (as a negative control). 


\section{Discussion}

We performed a yeast two-hybrid screen, using the HIV-1 p66 RT subunit as the bait, to characterize cellular cofactors involved in the reverse transcription step of the HIV1 replication cycle. We identified and validated an interaction between HIV-1 RT and the RNA-binding protein HuR. The HuR interaction site was mapped to the C-terminal part of the p66 RT subunit. This region, belonging to the RNase H domain, is freely accessible on the RT and extends to the vicinity of the primer-template. The p66 RT-HuR interaction was confirmed in vitro by an HTRF assay, suggesting that there was a direct interaction between HuR and p66 RT. However, since both HuR and RT are RNA binding proteins it could be possible that their interaction be mediated by RNA. Indeed, other interactions involving HuR have been shown to be RNA dependent, like the interaction between HuR and APOBEC3G [34]. HTRF assays conducted in the presence of RNAse did not allowed us to draw clear conclusions, since upon this treatment we obtained a slight and inconstant inhibition of the interaction signal (data not shown). Therefore, this question remains an open question that will need further investigations to be solved.

By silencing HuR expression with three different siRNAs targeting three different sites in the HuR mRNA sequence, we demonstrated that HuR expression was required for an optimal HIV-1 replication cycle and for both the early and late steps of reverse transcription, in particular. The enhancement of the reverse transcription reaction observed when HuR was overexpressed is consistent with these results. The absence of HuR affected wild type HIV1 , but also a non-replicative HIV-1 $\Delta$ Env-luciferase virus pseudotyped with the VSV-G envelope glycoprotein. As previously described, the entry pathways of these viruses are clearly differents [35]. While the wild type virus, bearing gp41/gp120, enters by fusion at the cell surface, VSV$\mathrm{G}$ targets the virus to endocytosis and fusion in the endosomes. Although one cannot exclude this possibility, an effect of HuR on both entry pathways, in addition to its effect on reverse transcription, would be very unlikely. The effect of HuR seemed to be specific to the reverse transcription step in HIV target cells, as HuR silencing in HIV1 producer cells had no effect on the production of viral particles or the infectivity of these newly released particles. Moreover, no incorporation of HuR into virions was observed, indicating that the HuR protein affecting reverse transcription was that present in the target cell, and not that in the producer cell.

The major role of HuR is to stabilize ARE-containing messenger RNAs (reviewed in $[36,37]$ ). This property of HuR seems to be related to its nucleocytoplasmic shuttling $[8,38,39]$, following cellular stresses such as heat shock, exposure to UV light or infection [40]. Indeed, previous studies have reported the binding of HuR to the RNAs of various viruses, including HPV-1, HPV-16, Herpesvirus saimiri and HCV $[28,31,32,41,42]$. However, no interference of HuR with HIV-1 RNA has been reported in previous studies.

We identified a putative HuR binding motif, based on recent studies by Lopez de Silanes et al. [24]. We mutated this motif to disrupt the U-rich region. No effect on HIV replication was observed. Moreover, RNA-immunoprecipitation studies provided no evidence of an association between the HIV-1 RNA and HuR. This suggests that the mode of action of $\mathrm{HuR}$ in $\mathrm{HIV}-1$ reverse transcription is based on its interaction with p66 RT rather than its interaction with the HIV-1 RNA. HuR plays a major role in stabilizing mRNAs, by binding to ARE elements, but previous studies have demonstrated protein-protein interactions involving HuR and playing an important role in the regulation of HuR activity [43-45]. One such interaction - with the RanGTP-binding nuclear transport receptor transportin 2 - was recently highlighted [46]. This interaction probably occurs in the cytoplasm, mediating the nuclear import of HuR. This interaction is optimal in the absence of RNA bound to HuR, suggesting that HuR is imported into the nucleus only when not bound to mRNA. The nucleocytoplasmic shuttling of HuR that seems to be responsible for mRNA stabilization was observed by Wang et al. upon T-cell activation, following the engagement of the integrin leukocyte function-associated molecule-1 (LFA-1) [10]. Several groups have previously reported the importance of LFA-1 for HIV infection and transmission to T cells [47-51]. As activated T cells are the preferred target cells for HIV infection, whereas unactivated T cells are very poorly infected by HIV, it is tempting to speculate that an absence of nucleocytoplasmic shuttling of HuR in unactivated T cells is correlated with the refractory state of these cells to HIV infection, together with other important recently discovered factors, such as the low molecular weight form of APOBEC 3G in these cells [52]. HuR has also been found in stress granules [9], together with APOBEC 3G [34], and is now considered to be a marker of these bodies. Is the ability of HuR to bind to p66 RT, positively affecting the reverse transcription of HIV-1 related to the nucleocytoplasmic shuttling property of HuR? Further work will be required to answer this important question.

In conclusion, we have identified a new cellular partner of HIV-1 reverse transcriptase: HuR. By modulating HuR levels, we were able to affect the infection of cells by HIV. However, the mechanism by which HuR influences the reverse transcription process remains to be elucidated. 


\section{Abbreviations}

HIV-1: human immunodeficiency virus type 1; RT: reverse transcriptase; siRNA: short interfering RNA; MOI: multiplicity of infection; GST: glutathione S-transferase; WT: wild type; HTRF: homogenous time-resolved fluorescence assay; VSV-G: vesicular stomatitis virus glycoprotein.

\section{Authors' contributions}

JL designed and performed the siRNA experiments for analysis of infection, viral production and infectivity, produced the RT proteins, performed the HTRF experiments, and wrote the manuscript, PMP constructed and produced GST-HuR protein and the ARE-mutant, TB designed the HTRF experiments, EE mapped the HuR binding site on RT, JCR performed the yeast two-hybrid screening, RB conceived the study, participated to data analysis and contributed to the writing of the manuscript, LXL designed and performed the siRNA experiments for analysis of RT products by qPCR, analysed HuR incorporation into viral particles and its interaction with HIV-1 mRNA, and contributed to the writing of the manuscript. All authors read and approved the final manuscript.

\section{Acknowledgements}

We thank G. Maga for kindly providing the plasmid encoding the $6 x \mathrm{His}-$ tagged recombinant HIV-I RT, C. Berlioz-Torrent and S. Emiliani for helpful discussions and support, and L. Boutin for technical assistance.

J.L was supported by doctoral fellowships from ANRS and FRM. L.L was supported by a postdoctoral fellowship from EC project TRIoH (LSHB-CT2003-503480). This work was supported by grants from the ANRS, the FRM, SIDACTION, ANR, and by grants from the European $6^{\text {th }}$ Framework Program for Research and Development via the Integrated Project TRIOH $n^{\circ}$ LSHB-CT-2003-503.

\section{References}

I. Telesnitsky A, Goff SP: Reverse Transcriptase and the Generation of Retroviral DNA. In Retroviruses Edited by: Coffin JM, Hughes SH, Varmus HE. Plainview, NY I I803: Cold Spring Harbor Press; 1997.

2. di Marzo Veronese F, Copeland TD, DeVico AL, Rahman R, Oroszlan S, Gallo RC, Sarngadharan MG: Characterization of highly immunogenic p66/p5I as the reverse transcriptase of HTLV-III/ LAV. Science |986, 231:|289-|29|.

3. Nisole S, Saib A: Early steps of retrovirus replicative cycle. Retrovirology 2004, I:9.

4. Hooker CW, Harrich D: The first strand transfer reaction of HIV-I reverse transcription is more efficient in infected cells than in cell-free natural endogenous reverse transcription reactions. J Clin Virol 2003, 26:229-238.

5. Warrilow D, Meredith L, Davis A, Burrell C, Li P, Harrich D: Cell Factors Stimulate HIV-I Reverse Transcription In Vitro. J Virol 2008.

6. Hottiger M, Gramatikoff K, Georgiev O, Chaponnier C, Schaffner W, Hubscher U: The large subunit of HIV-I reverse transcriptase interacts with beta-actin. Nucleic Acids Res 1995, 23:736-74I.

7. Orlova M, Yueh A, Leung J, Goff SP: Reverse transcriptase of Moloney murine leukemia virus binds to eukaryotic release factor I to modulate suppression of translational termination. Cell 2003, I I 5:319-331.

8. Fan XC, Steitz JA: Overexpression of HuR, a nuclear-cytoplasmic shuttling protein, increases the in vivo stability of AREcontaining mRNAs. Embo J 1998, I 7:3448-3460.
9. Kedersha N, Anderson P: Stress granules: sites of mRNA triage that regulate mRNA stability and translatability. Biochem Soc Trans 2002, 30:963-969.

10. Wang JG, Collinge M, Ramgolam V, Ayalon O, Fan XC, Pardi R, Bender JR: LFA-I-dependent HuR nuclear export and cytokine mRNA stabilization in T cell activation. I Immunol 2006, I76:2105-2113.

II. Wang W, Caldwell MC, Lin S, Furneaux H, Gorospe M: HuR regulates cyclin A and cyclin B I mRNA stability during cell proliferation. Embo J 2000, 19:2340-2350.

12. Atasoy U, Watson J, Patel D, Keene JD: ELAV protein HuA (HuR) can redistribute between nucleus and cytoplasm and is upregulated during serum stimulation and $T$ cell activation. J Cell Sci I 998, I I I (Pt 2 I):3 | 45-3 I 56.

13. Emiliani S, Mousnier A, Busschots K, Maroun M, Van Maele B, Tempe D, Vandekerckhove L, Moisant F, Ben-Slama L, Witvrouw M, et al.: Integrase mutants defective for interaction with LEDGF/p75 are impaired in chromosome tethering and HIV-I replication. J Biol Chem 2005, 280:25517-25523.

14. Fromont-Racine M, Rain JC, Legrain P: Building protein-protein networks by two-hybrid mating strategy. Methods Enzymol 2002, 350:513-524.

15. Vojtek AB, Hollenberg SM: Ras-Raf interaction: two-hybrid analysis. Methods Enzymol 1995, 255:331-342.

16. Maga G, Amacker M, Ruel N, Hubscher U, Spadari S: Resistance to nevirapine of HIV-I reverse transcriptase mutants: loss of stabilizing interactions and thermodynamic or steric barriers are induced by different single amino acid substitutions. J Mol Biol 1997, 274:738-747.

17. Adachi A, Gendelman HE, Koenig S, Folks T, Willey R, Rabson A, Martin MA: Production of acquired immunodeficiency syndromeassociated retrovirus in human and nonhuman cells transfected with an infectious molecular clone. J Virol 1986, 59:284-291.

18. Ho SN, Hunt HD, Horton RM, Pullen JK, Pease LR: Site-directed mutagenesis by overlap extension using the polymerase chain reaction. Gene 1989, 77:51-59.

19. Clavel F, Charneau P: Fusion from without directed by human immunodeficiency virus particles. J Virol 1994, 68: I I79-1 I 85.

20. Brussel A, Sonigo P: Analysis of early human immunodeficiency virus type I DNA synthesis by use of a new sensitive assay for quantifying integrated provirus. J Virol 2003, 77:101 19-10124.

21. Maroun M, Delelis O, Coadou G, Bader T, Segeral E, Mbemba G, Petit C, Sonigo P, Rain JC, Mouscadet JF, et al.: Inhibition of early steps of HIV-I replication by SNF5/Inil. J Biol Chem 2006, 28 I :22736-22743.

22. Zuker M: Mfold web server for nucleic acid folding and hybridization prediction. Nucleic Acids Res 2003, 3 I:3406-34I 5.

23. Lal A, Kawai T, Yang X, Mazan-Mamczarz K, Gorospe M: Antiapoptotic function of RNA-binding protein HuR effected through prothymosin alpha. Embo J 2005, 24: I852-1862.

24. Lopez de Silanes I, Zhan M, Lal A, Yang X, Gorospe M: Identification of a target RNA motif for RNA-binding protein HuR. Proc Natl Acad Sci USA 2004, I 0 I:2987-2992.

25. Fromont-Racine M, Rain JC, Legrain P: Toward a functional analysis of the yeast genome through exhaustive two-hybrid screens. Nat Genet 1997, 16:277-282.

26. Bazin H, Preaudat M, Trinquet E, Mathis G: Homogeneous time resolved fluorescence resonance energy transfer using rare earth cryptates as a tool for probing molecular interactions in biology. Spectrochim Acta A Mol Biomol Spectrose 200I, 57:2197-22।I.

27. Bazin $H$, Trinquet $E$, Mathis $G$ : Time resolved amplification of cryptate emission: a versatile technology to trace biomolecular interactions. J Biotechnol 2002, 82:233-250.

28. Cook HL, Mischo HE, Steitz JA: The Herpesvirus saimiri small nuclear RNAs recruit AU-rich element-binding proteins but do not alter host AU-rich element-containing mRNA levels in virally transformed T cells. Mol Cell Biol 2004, 24:4522-4533.

29. Esclatine A, Taddeo B, Roizman B: Herpes simplex virus I induces cytoplasmic accumulation of TIA-I/TIAR and both synthesis and cytoplasmic accumulation of tristetraprolin, two cellular proteins that bind and destabilize AU-rich RNAs. J Virol 2004, 78:8582-8592.

30. Mclnerney GM, Kedersha NL, Kaufman RJ, Anderson P, Liljestrom P: Importance of eIF2alpha phosphorylation and stress granule 
assembly in alphavirus translation regulation. Mol Biol Cell 2005, 16:3753-3763.

31. Spangberg K, Wiklund L, Schwartz S: HuR, a protein implicated in oncogene and growth factor mRNA decay, binds to the 3' ends of hepatitis C virus RNA of both polarities. Virology 2000, 274:378-390.

32. Sokolowski M, Furneaux H, Schwartz S: The inhibitory activity of the AU-rich RNA element in the human papillomavirus type I late 3' untranslated region correlates with its affinity for the elav-like HuR protein. J Virol 1999, 73:1080-I09I.

33. Chen $C Y$, Shyu $A B$ : Selective degradation of early-responsegene mRNAs: functional analyses of sequence features of the AU-rich elements. Mol Cell Biol 1994, 14:847|-8482.

34. Gallois-Montbrun S, Kramer B, Swanson CM, Byers H, Lynham S, Ward M, Malim MH: Antiviral protein APOBEC3G localizes to ribonucleoprotein complexes found in $P$ bodies and stress granules. J Virol 2007, 81:2165-2178.

35. Aiken C: Pseudotyping human immunodeficiency virus type I (HIV-I) by the glycoprotein of vesicular stomatitis virus targets HIV-I entry to an endocytic pathway and suppresses both the requirement for Nef and the sensitivity to cyclosporin A. J Virol 1997, 71:587I-5877.

36. Brennan CM, Steitz JA: HuR and mRNA stability. Cell Mol Life Sci 200I, 58:266-277.

37. Mitchell $P$, Tollervey D: mRNA stability in eukaryotes. Curr Opin Genet Dev 2000, 10:193-198.

38. Fan XC, Steitz JA: HNS, a nuclear-cytoplasmic shuttling sequence in HuR. Proc Natl Acad Sci USA 1998, 95: $15293-15298$.

39. Gallouzi IE, Steitz JA: Delineation of mRNA export pathways by the use of cell-permeable peptides. Science 200I, 294: I895-190I.

40. Wang W, Furneaux $\mathrm{H}$, Cheng $\mathrm{H}$, Caldwell MC, Hutter $\mathrm{D}$, Liu $\mathrm{Y}$, Holbrook N, Gorospe M: HuR regulates p2I mRNA stabilization by UV light. Mol Cell Biol 2000, 20:760-769.

41. Carlsson A, Schwartz S: Inhibitory activity of the human papillomavirus type I AU-rich element correlates inversely with the levels of the elav-like HuR protein in the cell cytoplasm. Arch Virol 2000, 145:49I-503.

42. Koffa MD, Graham SV, Takagaki Y, Manley JL, Clements JB: The human papillomavirus type 16 negative regulatory RNA element interacts with three proteins that act at different posttranscriptional levels. Proc Natl Acad Sci USA 2000, 97:4677-4682.

43. Brennan CM, Gallouzi IE, Steitz JA: Protein ligands to HuR modulate its interaction with target mRNAs in vivo. J Cell Biol 2000 I 5 I:I-I4.

44. Malek SN, Katumuluwa Al, Pasternack GR: Identification and preliminary characterization of two related proliferation-associated nuclear phosphoproteins. I Biol Chem 1990, 265:13400-13409.

45. Mencinger M, Panagopoulos I, Contreras JA, Mitelman F, Aman P: Expression analysis and chromosomal mapping of a novel human gene, APRIL, encoding an acidic protein rich in leucines. Biochim Biophys Acta 1998, I395: 176-180.

46. Guttinger S, Muhlhausser P, Koller-Eichhorn R, Brennecke J, Kutay U: Transportin2 functions as importin and mediates nuclear import of HuR. Proc Natl Acad Sci USA 2004, 101:2918-2923.

47. Hioe CE, Chien PC Jr, Lu C, Springer TA, Wang XH, Bandres J, Tuen M: LFA-I expression on target cells promotes human immunodeficiency virus type I infection and transmission. I Virol 2001, 75: 1077-1082.

48. Groot F, Kuijpers TW, Berkhout B, de Jong EC: Dendritic cellmediated HIV-I transmission to T cells of LAD-I patients is impaired due to the defect in LFA-I. Retrovirology 2006, 3:75.

49. Tardif MR, Tremblay MJ: LFA-I is a key determinant for preferential infection of memory CD4+ $T$ cells by human immunodeficiency virus type I. J Virol 2005, 79:137|4-13724.

50. Tardif MR, Tremblay MJ: Regulation of LFA-I activity through cytoskeleton remodeling and signaling components modulates the efficiency of HIV type-I entry in activated CD4+ T lymphocytes. J Immunol 2005, 175:926-935.

5I. Fortin JF, Cantin R, Tremblay MJ: T cells expressing activated LFA-I are more susceptible to infection with human immunodeficiency virus type I particles bearing host-encoded ICAM-I. J Virol 1998, 72:2105-2II2.
52. Chiu YL, Soros VB, Kreisberg JF, Stopak K, Yonemoto W, Greene WC: Cellular APOBEC3G restricts HIV-I infection in resting CD4+ T cells. Nature 2005, 435: I08-II4.

53. Ding J, Das K, Hsiou Y, Sarafianos SG, Clark AD Jr, Jacobo-Molina A Tantillo C, Hughes SH, Arnold E: Structure and functional implications of the polymerase active site region in a complex of HIV-I RT with a double-stranded DNA template-primer and an antibody Fab fragment at 2.8 A resolution. J Mol Biol 1998, 284: $1095-1||$ I.
Publish with Bio Med Central and every scientist can read your work free of charge

"BioMed Central will be the most significant development for disseminating the results of biomedical research in our lifetime. "

Sir Paul Nurse, Cancer Research UK

Your research papers will be:

- available free of charge to the entire biomedical community

- peer reviewed and published immediately upon acceptance

- cited in PubMed and archived on PubMed Central

- yours - you keep the copyright 